\title{
Kuliah Lapangan Terpadu Berbasis Inkuiri untuk Meningkatkan Penguasaan Konsep Mahasiswa Pendidikan Biologi
}

\author{
Yusuf Ibrahim ${ }^{1,2}$ a), Hertien K Surtikanti ${ }^{1}$ ), Riandi ${ }^{1}$ ) \\ 1)Pendidikan Biologi, Universitas Pendidikan Indonesia, Jl. Dr. Setiabudi No. 229, Bandung 40154, \\ Indonesia \\ $\left.{ }^{2}\right)$ Pendidikan Biologi, Universitas Pasundan Bandung, Jl Tamansari No 6-8, Bandung, Indonesia \\ a)Email: yusuf.ibrahim@unpas.ac.id
}

\begin{abstract}
Abstrak
Kuliah lapangan merupakan pengalaman belajar penting bagi mahasiswa calon guru biologi. Tujuan dari penelitian ini adalah untuk mengetahui peningkatan penguasaan konsep mahasiswa melalui pengalaman belajar kuliah lapangan terpadu berbasis inkuiri. Subjek penelitian dalam penelitian ini adalah mahasiswa calon guru biologi di salah satu iniversitas swasta di kota Bandung $(n=30)$. Instrumen yang digunakan dalam penelitian ini adalah tes penguasaan konsep. Metodologi penelitian yang digunakan dalam penelitian ini adalah metode kuasi ekperimen dengan desain one group postes postes design. Hasil penelitian menunjukan bahwa implementasi pengalaman belajar kuliah lapangan terpadu berbasis inkuiri dapat meningkatkan penguasaan konsep mahasiswa calon guru biologi $(\mathrm{N}$-gain=0,62). Pengalaman belajar melalui kuliah lapangan terpadu berbasis inkuiri dapat membantu mahasiswa meningkatkan penguasaan konsepnya.
\end{abstract}

Kata kunci: Kuliah lapangan terpadu, penguasaan konsep

\begin{abstract}
Fieldtrip is learning experience which is important for biology student teacher. The aim of this study is to find out the enhancement of concept mastery among students through inquiry based-integrated fieldtrip learning experience. The subjects of this study are biology student teachers in one private university in Bandung City $(n=30)$. The instrument used in this study is concept mastery test. The research methodology used in this study is experimental quasi with one group pretest posttest design. The result of study showed that implementation of inquiry based-integrated fieldtrip learning experience can enhance concept mastery of biology student teacher $(N$-gain $=0.62)$. Learning experience through inquiry can help students to enhance their concept mastery.
\end{abstract}

Keyword: integrated fieldtrip, concept mastery

\section{PENDAHULUAN}

Kuliah lapangan merupakan pengalaman belajar penting bagi mahasiswa, khususnya mahasiswa calon guru biologi. Kuliah lapangan terpadu yang dilakukan akan memberi peluang kepada mahasiswa untuk mengeksplorasi objek kajian secara utuh dan otentik. Patrick (2010) mengemukakan bahwa: "Field trip is an outdoor or field work or learning exercise undertaken by teachers and students in certain aspects of subjects particularly, biology so as to give the students the opportunity to acquire knowledge'.

Kuliah Lapangan dapat memberikan banyak kesempatan kepada mahasiswa untuk mendapatkan banyak pengetahuan. Hudak (2003) yang menyatakan bahwa kuliah lapangan dapat mengembangkan hubungan antara teori atau konsep yang siswa dapatkan di kelas dengan pengalaman yang siswa dapatkan me- lalui kuliah lapangan. Selain itu, kuliah lapangan juga dapat meningkatkan dan mengembangkan pengetahuan siswa (Hudak, 2003; Kisiel, 2006; Mawdsley, 1999; Michie, 1998; Nadelson \& Jordan, 2012; Scarce, 1997; Scribner-MacLean \& Kennedy, 2007). Kuliah lapangan juga dapat mempertajam kemampuan melakukan observasi dan persepsi dengan menggunakan berbagai alat indera yang dimiliki siswa (Nabors, et al., 2009). Behrendt and Franklin, (2014) menyatakan bahwa kuliah lapangan dapat mengembangkan kemampuan berkomunikasi siswa. Hofstein and Orion (1991) juga menyatakan bahwa kuliah lapangan dapat meningkatkan kemampuan memecahkan masalah mahasiswa

Kuliah lapangan umumnya dilakukan secara terpisah baik yang menyangkut faktor biotik seperti flora dan fauna, maupun yang menyangkut faktor abiotik, seperti suhu, ke- 
lembapan, $\mathrm{pH}$, dan salinitas, sehingga tidak bisa mengeksplorasi lingkungan secara utuh dan sulit ketika dihadapkan pada masalah-masalah lingkungan yang kompleks. Banyak riset menunjukkan bahwa kegiatan kuliah lapangan masih sebatas mengunjungi objek-objek tertentu saja dan hanya bersifat pengayaan saja, sehingga tujuan pembelajaran yang ingin dicapai melalui kegiatan tersebut menjadi sangat terbatas, padahal dengan kuliah lapangan ada banyak hal yang bisa mahasiswa dapatkan apabila kegiatan tersebut dikelola dengan efektif. Penelitian mengenai bagaimana melaksanakan kuliah lapangan secara terpadu di pantai masih sedikit, selain itu kuliah lapangan masih sebatas memverifikasi kebenaran teori tanpa dibarengi kegiatan mencari hubungan dan keterpaduan antara makhluk hidup yang satu dengan makhluk hidup yang lainnya dan makhluk hidup dengan faktor abiotik yang berada di habitat aslinya.

Penelitian ini bertujuan untuk mengetahui peningkatan pemahaman konsep mahasiswa setelah implementasi kuliah lapangan terpadu berbasis inkuiri. Penguasaan konsep oleh mahasiswa merupakan hal yang penting dimiliki karena hal tersebut merupakan kemampuan dasar untuk mendapatkan kemampuan lainnya.

\section{METODE PENELITIAN}

Penelitian ini merupakan penelitian quasi eksperimen yang bertujuan untuk mengetahui pengaruh implementasi kuliah lapangan terpadu berbasis inkuiri terhadap penguasaan konsep mahasiswa. Penelitian ini dilaksanakan di Program Studi Pendidikan Biologi di salah satu universitas swasta di kota Bandung. Waktu pelaksanaannya adalah pada semester ganjil tahun ajaran 2014/2015. Subjek penelitiannya adalah mahasiswa tingkat akhir $(\mathrm{n}=30)$. Data penelitian berupa hasil tes penguasaan konsep yang dianalisis secara deskriptif dan kualitatif. Data hasil tes penguasaan konsep diperoleh melalui pretes dan postes, kemudian dihitung $\mathrm{N}$-gannya untuk mendapatkan gambaran peningkatan penguasaan konsepnya.

\section{HASIL DAN PEMBAHASAN}

Kuliah lapangan terpadu berbasis inkuiri berpengaruh positif terhadap penguasaan konsep mahasiswa. Pada setiap indikator pembelajaran, rata-rata mahasiswa memperoleh nilai di atas kriteria ketuntasan yang telah ditetapkan. Pencapaian penguasaan konsep pada setiap indikator pembelajaran dapat dilihat pada tabel di bawah ini:

Tabel 1. Perolehan Skor dan N-Gain Penguasaan Konsep

\begin{tabular}{|c|c|c|c|c|c|}
\hline \multirow{2}{*}{ No } & \multirow{2}{*}{ Indikator Pembelajaran } & \multicolumn{2}{|c|}{ Skor } & \multirow{2}{*}{ N-Gain } & \multirow{2}{*}{ Kategori } \\
\hline & & Pretes & Postes & & \\
\hline 1 & $\begin{array}{l}\text { Mahasiswa mampu mengorganisasi kegiatan studi lapangan, dan } \\
\text { mengkomunikasikan hasilnya melalui laporan dan secara lisan }\end{array}$ & 76 & 100 & 1,00 & tinggi \\
\hline 2 & $\begin{array}{l}\text { Mahasiswa mampu menggunakan alat-alat penangkapan dan } \\
\text { penanganan yang digunakan untuk hewan nvertebrata dan tumbuhan } \\
\text { cryptogamae }\end{array}$ & 93 & 97 & 0,50 & Sedang \\
\hline 3 & $\begin{array}{l}\text { Mahasiswa mampu mengidentifikasi hewan invertebrata diantara } \\
\text { hewan yang ditangkap dari lingkungan }\end{array}$ & 93 & 100 & 1,00 & Tinggi \\
\hline 4 & $\begin{array}{l}\text { Mahasiswa mampu mengidentifasi keanekaragaman hewan zoology } \\
\text { invertebrata melalui observasi }\end{array}$ & 69 & 86 & 0,56 & Sedang \\
\hline 5 & $\begin{array}{l}\text { Mahasiswa mampu mengidentifasi dan mengkomunikasikan ciri } \\
\text { morfologi hewan invertebrate yang ditemuinya }\end{array}$ & 52 & 69 & 0,36 & Sedang \\
\hline 6 & $\begin{array}{l}\text { Mahasiswa mampu mengkomunikasikan hasil pengamatan hewan } \\
\text { invertebrata dalam bentuk tulisan/gambar maupun lisan }\end{array}$ & 34 & 76 & 0,63 & Sedang \\
\hline 7 & $\begin{array}{l}\text { Mahasiswa mampu mengenali hewan invertebrata berdasarkan ciri } \\
\text { morfologinya dan meletakkannya dalam kedudukan taksonominya }\end{array}$ & 31 & 79 & 0,70 & Tinggi \\
\hline 8 & $\begin{array}{l}\text { Mahasiswa mampu mengidentifikasi tumbuhan cryptogamae diantara } \\
\text { tumbuhan yang ditangkap dari lingkungan perairan pantai }\end{array}$ & 48 & 76 & 0,53 & Sedang \\
\hline 9 & $\begin{array}{l}\text { Mahasiswa mampu mengidentifasi keanekaragaman tumbuhan } \\
\text { cryptogamae melalui observasi di lingkungan pantai }\end{array}$ & 45 & 90 & 0,81 & Tinggi \\
\hline 10 & $\begin{array}{l}\text { Mahasiswa mampu mengidentifasi dan mengkomunikasikan ciri } \\
\text { morfologi tumbuhan cryptogamae yang ditemuinya di lingkungan } \\
\text { perairan pantai }\end{array}$ & 0 & 76 & 0,76 & Tinggi \\
\hline 11 & $\begin{array}{l}\text { Mahasiswa mampu mengkomunikasikan hasil pengamatan tumbuhan } \\
\text { cryptogamae dalam bentuk tulisan/gambar maupun lisan }\end{array}$ & 66 & 83 & 0,50 & Sedang \\
\hline 12 & $\begin{array}{l}\text { Mahasiswa mampu mengenali tumbuhan cryptogamae berdasarkan } \\
\text { ciri morfologinya }\end{array}$ & 14 & 69 & 0,64 & Sedang \\
\hline 13 & $\begin{array}{l}\text { menjelaskan hasil data observasi lapangan yang diperoleh selama } \\
\text { kuliah lapangan }\end{array}$ & 48 & 83 & 0,67 & Sedang \\
\hline 14 & Memahami dan menerapkan pemahaman konsep-konsep Ekologi & 45 & 66 & 0,38 & Sedang \\
\hline
\end{tabular}




\begin{tabular}{|c|c|c|c|c|c|}
\hline \multirow{2}{*}{ No } & \multirow{2}{*}{ Indikator Pembelajaran } & \multicolumn{2}{|c|}{ Skor } & \multirow{2}{*}{ N-Gain } & \multirow{2}{*}{ Kategori } \\
\hline & & Pretes & Postes & & \\
\hline & dalam kehidupan sehari-hari & & & & \\
\hline 15 & $\begin{array}{l}\text { Memahami dan menerapkan pemahaman konsep-konsep Ekologi } \\
\text { dalam kehidupan sehari-hari }\end{array}$ & 79 & 86 & 0,33 & Sedang \\
\hline 16 & $\begin{array}{l}\text { Melatih keterampilan mahasiswa dalam menerapkan teknik-teknik } \\
\text { sampling organisme }\end{array}$ & 48 & 76 & 0,35 & Sedang \\
\hline 17 & $\begin{array}{l}\text { Melakukan pengukuran klimatik (pH, suhu, kedalaman, penetrasi } \\
\text { cahaya, salinitas, dan kecepatan arus) }\end{array}$ & 66 & 86 & 0,60 & Sedang \\
\hline \multirow[t]{2}{*}{18} & $\begin{array}{l}\text { Menganalisis keterkaitan antara faktor abiotik dengan sebaran hewan } \\
\text { invertebrata dan tumbuhan cryptogamae }\end{array}$ & 52 & 79 & 0,57 & Sedang \\
\hline & Rata-rata & $\mathbf{5 1 , 5 0}$ & 82,00 & 0,62 & Sedang \\
\hline
\end{tabular}

Pada keadaaan awal kemampuan penguasaan konsep mahasiswa berada pada angka 51,5. Pada kategori penguasaan kemampuan menurut Arikunto (2002) berada pada kategori kurang, berdasarkan skor pada setiap indikator kemampuan memecahkan masalah mahasiswa masih kesulitan dalam hal: menyajikan masalah dalam bentuk yang lebih jelas, menyususn hipotesis alternatif dan prosedur kerja, mengetes hipotesis dan melakukan kerja untuk memperoleh data serta memeriksa kembali data yang sudah diperoleh. Setelah mahasiswa melakuan kuliah lapangan terpadu menunjukan adanya peningkatan skor penguasaan konsep dengan capaian skor kemampuan sebesar 82,00 berada pada kategori baik sekali berdasarkan kategori penguasaan kemampuan menurut arikunto (2002). Skor N-Gain menunjukan bahwa peningkatan penguasaan konsep setelah kuliah lapangan terpadu berbasis inkuiri mengalami peningkatan 0,62 berada pada kategori peningkatan sedang. Hasil uji berbedaan dua rerata menggunakan uji t terhadap data pretes dan postes penguasaan konsep mahasiswa diperoleh nilai t hitung $=25,18$ pada taraf signifikansi $\alpha=0,05$, berikut disajikan hasil perhitungan uji $t$ terhadap data pretes dan postes penguasaan konsep. Hasil uji t memperlihatkan bahwa terdapat perbedaan signifikan antara data pretes dan postes penguasaan konsep mahasiswa, hal tersebut menjadi indikator bahwa implementasi kuliah lapangan terpadu (integrative field trip) efektif untuk meningkatkan penguasaan konsep mahasiswa.

Dari data di atas diketahui bahwa kuliah lapangan terpadu berpengaruh positif terhadap penguasaan konsep mahasiswa. Pengalaman belajar pada kuliah lapangan terpadu memberi pengalaman nyata yang berpengaruh pada proses perolehan konsep oleh mahasiswa. Hattie, et al., (1997) menyatakan bahwa " $A d$ - venture-type field trip are found to have astrong effect on outcomes relating to identity, self-concept and motivational orientation, and tend to have a pronounced effect over time". Pengalaman belajar autentik telah menjadi suatu hal yang penting diupayakan untuk menciptakan situasi belajar yang bermaka

Hutson, at al (2011), menyatakan bahwa mayoritas mahasiswa percaya bahwa $S c i$ entific field trip membantu dalam meningkatkan pengetahuanya. Shakil, et. al (2011) juga menyatakan bahwa kuliah lapangan dapat membantu meningkatkan kemampuan kognitif dan kemampuan berinkuiri siswa. NRC (2009) menjelaskan bahwa siswa yang mendapat pengalaman belajar hands-on, pengalaman autentik akan mengembangkan rasa ingin tahu siswa dan minat siswa serta mendorong siswa untuk mempelajari sesuatu lebih dalam, hal tersebut tentunya akan berpengaruh terhadap kemampuan kognitif dan pengetahuan siswa tentang objek kajian yang dipelajari. Kuliah lapangan juga dapat mengembangkan hubungan antara teori atau konsep yang siswa dapatkan di kelas dengan pengalaman yang siswa peroleh dari kuliah lapangan (Falk, at al, 1978; Hudak, 2003). Dari beberapa penelitian yang telah dilakukan sebelumnya diketahui bahwa kuliah lapangan dapat membantu siswa dan mahasiswa untuk mengkonstruksi pengetahuan yang bermakna. Selain itu, adanya unsur keterpaduan dalam kajian konten materi kuliah pada saat mahasiswa melakukan kuliah lapangan juga berpengaruh positif terhadap proses perolehan pengetahuan mahasiswa. Adanya unsur keterpaduan menciptakan proses mental dan kognisi yang bermanfaat bagi mahasiswa pada saat memahami suatu fenomena yang ditemukan di lingkungan. Sa'ud dan Rukmana (2006) menyatakan bahwa pembelajaran terpadu dapat meningkatkan motivasi siswa untuk mengenal, menerima, menyerap dan memahami keterkaitan atau hubungan antar konsep, 
pengetahuan, nilai atau tindakan yang terdapat dalam beberapa pokok pembahasan.

\section{KESIMPULAN}

Hasil penelitian menunjukan bahwa kuliah lapangan terpadu berbasis inkuiri dapat meningkatkan penguasaan konsep mahasiswa $(\mathrm{N}-\mathrm{Gain}=0,62)$. Pengalaman berinteraksi langsung dengan objek kajian biologi selama kuliah lapangan, pengalaman belajar berinkuiri serta adanya unsur keterpaduan kajian dalam kuliah lapangan terpadu berbasis inkuiri dapat membantu mahasiswa meningkatkan pemahaman konsepnya.

\section{DAFTAR PUSTAKA}

Arikunto, Suharsimi. (2002). Metodologi Penelitian. Jakarta : PT. Rineka Cipta.

Behrendt, M. Dan Franklin, T. (2014). A Review of research on school field trips and their value in education. International Journal of Environmental \& Science Education, 9, 235-245

Falk, J. H., Martin, W. W., \& Balling, J. D. (1978). The novel field trip phenomenon: Adjustment to novel settings interferes with task learning. Journal of Research in Science Teaching, 15(2), 127-134

Hattie, J., Marsh, H. W., Neill, J. T., \& Richards, G. E. (1997). Adventure education andOutward Bound: Out-ofclass experiences that make a lasting difference. Review of Educational Researcher, 67, 43-87.

Hofstein, A and Orion, N. (1991) Factors which influence learningability duringa scientific field trip ina natural environment. The Department of Science Teaching Weizmann Institute of Science, Israel. A paper presented at the NARST 1991 conference, The Abbey, Fontana, Wisconsin, U.S.A.

Hudak, P. (2003). Campus field exercises for introductory geoscience courses. Journal of Geography, 102(5), 220225
Hutson, T., Cooper, S., \& Talbert, T. (2011). Describing connections between science content and future careers: Implementing Texas curriculum for rural at-risk high school students using purposefully-designed field trips. Rural Educator,31,37-47

Kisiel, J.,(2006). An Examination of Fieldtrip Strategies and Their Implementation Within a Natural Hystory Museum, Science Education ed. 90 :434-452.

Mawdsley. R. D. (1999). Legal issues involving fieldtrips. School Business Affairs, 65(9), 28-31

Michie, M. (1998). Factors influencing secondary science teachers to organise and conduct field trips. Australian Science Teacher's Journal, 44, 43-50

Nabors, M.L., Edwards, L.C., \& Murray, R.K. (2009). Making the case for field trips:What research tells us and what site coordinators have to say. Education 129(4), 661-667.

Nadelson, L., \& Jordan, J. (2012). Student attitudes toward and recall of outside day: An environmental science field trip. Journal of Educational Research, 105(3), 220-231

National Research Council (2009). Learning science in informal environments: People, places, and pursuits. Washington, DC: The National Academies Press

Orion, N. and Hofstein, A. (1991) Factors which influence learningability duringa scientific field trip ina natural environment. The Department of Science Teaching Weizmann Institute of Science, Israel. A paper presented at the NARST 1991 conference,The Abbey, Fontana, Wisconsin, U.S.A.

Patrick,A.O., (2010). Effect of Field Study on Learning Outcome in Biology, J.Hum.Ecol.,31/33:171-177.

Sa'ud, U.S. dan Rukmana, A. (2006). Pembelajaran Terpadu. Bandung: UPI Press

Scarce, R. (1997). Field trips as short term experiential education. Teaching Sociology, 25, 219-226. 
Schaal, S., Bogner F.X., \& Girwidz, R. (2010). Concept Mapping Assessment of Media Assisted Learning in Interdisciplinary Science Education. Research In Science Education, 40(3):pp 339-352
Scribner-MacLean, M., \& Kennedy, L. (2007). More than just a day away from school: Planning a great science field trip. Science Scope, 30(5), 57-60 